\title{
A Longitudinal Study of Low Back Pain and Daily Vibration Exposure in Professional Drivers
}

\author{
Massimo BOVENZI ${ }^{1}$ \\ ${ }^{1}$ Clinical Unit of Occupational Medicine, Department of Reproductive, Developmental and Public Health \\ Sciences, University of Trieste, Centro Tumori, Via della Pietà 19, I-34129 Trieste, Italy
}

Received July 9, 2009 and accepted May 17, 2010

\begin{abstract}
The aim of this study was to investigate the relation between low back pain (LBP) outcomes and measures of daily exposure to whole-body vibration (WBV) in professional drivers. In a study population of 202 male drivers, who were not affected with LBP at the initial survey, LBP in terms of duration, intensity, and disability was investigated over a two-year follow-up period. Vibration measurements were made on representative samples of machines and vehicles. The following measures of daily WBV exposure were obtained: (i) 8-h energy-equivalent frequency-weighted acceleration (highest axis), $A(8)_{\max }$ in $\mathrm{ms}^{-2}$ r.m.s.; (ii) $A(8)_{\text {sum }}$ (root-sum-of-squares) in $\mathrm{ms}^{-2}$ r.m.s.; (iii) Vibration Dose Value (highest axis), $\mathrm{VDV}_{\max }$ in $\mathrm{ms}^{-1.75}$; (iv) $\mathrm{VDV}_{\text {sum }}$ (root-sum-of-quads) in $\mathrm{ms}^{-1.75}$. The cumulative incidence of LBP over the followup period was $38.6 \%$. The incidence of high pain intensity and severe disability was 16.8 and $14.4 \%$, respectively. After adjustment for several confounders, $\mathrm{VDV}_{\text {max }}$ or $\mathrm{VDV}_{\text {sum }}$ gave better predictions of LBP outcomes over time than $A(8)_{\max }$ or $A(8)_{\text {sum }}$, respectively. Poor predictions were obtained with $A(8)_{\max }$, which is the currently preferred measure of daily WBV exposure in European countries. In multivariate data analysis, physical work load was a significant predictor of LBP outcomes over the follow-up period. Perceived psychosocial work environment was not associated with LBP.
\end{abstract}

Key words: Cohort study, Professional drivers, Low back pain, Whole-body vibration, Daily vibration exposure, Transition model

\section{Introduction}

Long-term exposure to whole-body vibration (WBV) in professional drivers of machines and/or vehicles used in industry, agriculture/forestry, and public utilities is associated with an excess risk for back symptoms and disorders of the lumbar tract of the spine ${ }^{1,2)}$. Epidemiological studies and reviews have reported a higher occurrence of low back pain (LBP), herniated disc and early degeneration of the spine in the exposed drivers than in either worker groups unexposed to WBV or the general population ${ }^{1,3-5)}$. Driving of vehicles involves not only exposure to harmful WBV but also to several ergonomic risk factors which can affect the spinal system, such as prolonged sitting and awkward postures. Moreover, some driving occupations involve heavy lifting and manual handling activities (e.g. drivers of delivery trucks), which are known to strain the lower part of the back. Individual characteristics (e.g. age, body mass, and smoking) and psychosocial factors are also suggested as potential predictors for $\mathrm{LBP}^{6}$. It follows that injuries in the lower back of professional drivers may be considered a complex of health disorders of multifactorial origin involving both occupational and non-occupational stressors.

The European (EU) Directive on mechanical vibration ${ }^{7)}$ provides qualitative and quantitative guidance to protect workers against the risks arising from exposure to vibration at work. In the EU Directive, WBV is defined as "the mechani-

E-mail: bovenzi@units.it cal vibration that, when transmitted to the whole body, entails risks to the health and safety of workers, in particular lowerback morbidity and trauma of the spine'. Quantitative requirements for WBV are in the form of "daily exposure action value" and "daily exposure limit value", which are expressed in terms of either eight-hour energy-equivalent frequencyweighted root-mean-square (r.m.s.) acceleration $\left(A(8)\right.$ in $\mathrm{ms}^{-2}$ r.m.s.) or Vibration Dose Value (VDV in $\mathrm{ms}^{-1.75}$ ). The highest (r.m.s.) value, or the highest VDV of the frequency-weighted acceleration $\left(a_{\mathrm{w}}\right)$, determined in three orthogonal axes $\left(1.4 a_{\mathrm{w}, \mathrm{X}}\right.$, $1.4 a_{\mathrm{w}, \mathrm{y}}, a_{\mathrm{w}, \mathrm{z}}$ for a seated or standing worker), are to be used for the evaluation of exposure severity. For WBV, the action value, that is the exposure value above which the employer must implement technical, administrative and medical surveillance measures for the protection of workers from risks to their health and safety, is set at either $A(8) 0.5 \mathrm{~ms}^{-2}$ r.m.s. or VDV $9.1 \mathrm{~ms}^{-1.75}$. The exposure limit value, that is the exposure value which shall never be exceeded, is set at either $A(8)$ $1.15 \mathrm{~ms}^{-2}$ r.m.s. or VDV $21 \mathrm{~ms}^{-1.75}$.

The national laws of European countries have, in general, adopted $A(8)$ as the preferred measure of daily exposure to WBV. It has been argued that $A(8)$, compared with VDV, may underestimate the adverse health effects of WBV in presence of transient vibration, shocks, or repetitive shocks. Moreover, the choice of a single (highest) vibration axis to calculate $A(8)$ or VDV has been debated, since multi-axis vibration (vector sum) might be more appropriate for certain types of machines or vehicles with comparable vibration in two or more axes.

The aim of this prospective cohort study was to investigate 
the relation between alternative measures of daily vibration exposure and the occurrence of LBP outcomes over time in a group of Italian professional drivers who were free from LBP at baseline. The drivers were recruited in a four-year research project entitled "Risks of Occupational Vibration Injuries" (VIBRISKS) and funded by the EU Commission ${ }^{8)}$. VIBRISKS is a European research project which seeks to improve understanding of the risk of injury from occupational exposures to mechanical vibration by means of epidemiological studies supported by fundamental laboratory research.

\section{Subjects and Methods}

\section{Study population}

The VIBRISKS project included a work package devoted to epidemiological studies of the adverse effects of WBV on musculoskeletal system. Researchers from four European countries were involved in WBV epidemiological work (Italy, Sweden, the Netherlands, United Kingdom). In Italy, the study population included all male professional drivers $(n=628)$ employed in several industries (marble quarries, marble laboratories, dockyards, paper mills) and public utilities (garbage services, public transport) located in various Provinces of Italy. The rate of participation in the initial cross-sectional survey in the calendar period October 2003 to February 2004 was $95.2 \%(n=598)$. In this longitudinal study, the incidence of LBP, daily vibration exposure, and other work-related risk factors were investigated in a cohort of 202 drivers who were not affected with LBP in the previous 12 months at the initial survey. Of these, 110 subjects participated in two followup investigations carried out in the same calendar periods in 2004-2005 and 2005-2006. Owing to either organisational problems due to time schedules at the workplace or opposition by the employers, 92 drivers could participate in one-year follow-up survey solely.

Written informed consent to the study was obtained from employers and employees at each company.

A minimum of one year of professional driving in the current job was established as the basic criterion for the inclusion of drivers in the study population.

Table 1 reports the distribution of the study population by industry and machinery. Drivers were divided into three

Table 1. Distribution of the professional drivers with no low back pain in the previous 12 months at baseline, by industry and machinery $(n=202)$

\begin{tabular}{|c|c|c|c|}
\hline Group & $\mathrm{N}$ & Industry & Machine/vehicle \\
\hline A & 49 & $\begin{array}{l}\text { Marble quarries } \\
\text { Marble laboratories }\end{array}$ & $\begin{array}{l}\text { Earth-moving machines (wheel } \\
\text { loader, excavator, rock crusher) } \\
\text { Articulated dumper } \\
\text { Off-road car }\end{array}$ \\
\hline B & 67 & $\begin{array}{l}\text { Marble laboratories } \\
\text { Dockyards } \\
\text { Paper mills }\end{array}$ & $\begin{array}{l}\text { Fork-lift truck } \\
\text { Track-type loader } \\
\text { Freight-container tractor } \\
\text { Mobile crane }\end{array}$ \\
\hline $\mathrm{C}$ & 86 & $\begin{array}{l}\text { Public utilities } \\
\text { Public transport }\end{array}$ & $\begin{array}{l}\text { Garbage truck } \\
\text { Garbage compactor } \\
\text { Bus }\end{array}$ \\
\hline
\end{tabular}

groups according to the machines and/or vehicles more frequently used in their work activities: earth-moving machines in marble quarries and laboratories for Group A, fork-lift trucks in marble laboratories, dockyards and paper mills for Group B, buses in public transport and garbage machines in public services for Group C.

\section{Interview and $L B P$ outcomes}

The drivers were interviewed by certified occupational health personnel who were trained to administer a structured questionnaire developed within the VIBRISKS project $^{9,}$ 10). For this purpose, specific meetings were organised to test the method of administration of the questionnaire to workers.

The questionnaire consisted of five major sections which have been described in detail in our previous paper ${ }^{11)}$. Briefly, in addition to items on the subject's personal characteristics (age, height, weight, smoking and drinking habits, education, marital status, physical activity, and annual car driving), the questionnaire requested information on occupational history in the current and previous companies with details about job titles, duration of employment, types of machines or vehicles driven, daily and cumulative duration of driving on specific machine or vehicle, physical load during a typical working day (walking and standing, sitting, non-neutral postures, lifting), and aspects related to psychosocial factors at work (job decision, job support from supervisors or co-workers, job satisfaction). LBP was investigated using a modified version of the Nordic questionnaire on musculoskeletal symptoms ${ }^{12}$.

LBP was defined as pain or discomfort in the low back area between the twelfth ribs and the gluteal folds (indicated in a figure), with or without radiating pain in one or both legs, lasting one day or longer in the previous $7 \mathrm{~d}$ and the previous 12 months. Workers who reported LBP were requested to answer to additional questions concerning duration, frequency, pain radiation, pain intensity and disability, health care use because of symptoms, treatment (e.g. anti-inflammatory drugs or physical therapy), and sick leave due to symptoms in the previous 12 months.

Pain intensity in the last 12 months was rated on an 11-point scale, where 0 is "no pain at all" and 10 is "pain as bad as it could be" according to the Numerical Rating Scale (NRS) method ${ }^{13)}$.

Disability due to the last episode of LBP in the previous 12 months was measured by means of the Roland and Morris $(\mathrm{R} \& \mathrm{M})$ disability scale $\left.{ }^{14}\right)$. The workers were requested to answer 24 questions concerning daily life activities which were impaired by LBP, such as standing up, walking, bending, getting dressed, getting out of a chair, etc. A disability scale score for each worker suffering from LBP in the previous 12 months was obtained by summing up the number of disability conditions experienced by the affected worker.

In this study the outcome was LBP in the previous 12 months treated as a three-level ordinal scale response variable expressed in terms of duration of $\operatorname{LBP}(0,1-6, \geq 7 \mathrm{~d})$, pain intensity (NRS score: $0,1-5,6-10)$, and disability (R\&M scale score: $0,1-12,13-24)$.

\section{Measurement and assessment of daily vibration exposure}

Vibration measurements were made on representative samples of industrial machines and vehicles $(n=68)$ used by the 
professional drivers. Vibration was measured at the driverseat interface during actual operating conditions according to the recommendations of the International Standard ISO 2631-1 (1997) and the VIBRISKS protocol ${ }^{15,16)}$. Details of the vibration measurements and sampling procedures are reported elsewhere ${ }^{11,17)}$.

From one-third octave band frequency spectra $(1-80 \mathrm{~Hz})$ recorded from $x$-, $y$-, and $z$-directions, frequency-weighted accelerations $\left(a_{\mathrm{w}, x}, a_{\mathrm{w}, y}, a_{\mathrm{w}, z}\right)$ were obtained by using the weighting factors suggested in ISO 2631-1 ${ }^{16)}$.

Vibration signals were averaged by using the root-meansquare (r.m.s.) method and the root-mean-quad (r.m.q.) method.

The r.m.s. value is given by:

$$
a_{\text {r.m.s. }}=\left[\frac{1}{T} \int_{t=0}^{t=T} a^{2}(t) \mathrm{d} t\right]^{1 / 2}
$$

The r.m.q. value is given by:

$$
a_{\text {r.m.q. }}=\left[\frac{1}{T} \int_{t=0}^{t=T} a^{4}(t) \mathrm{d} t\right]^{1 / 4}
$$

The root-sums-of-squares (sometimes referred to as the 'vector sum' or 'total value', $a_{\mathrm{ws}}$ ) of the r.m.s. acceleration values for each machine or vehicle was calculated according to the following formula:

$$
a_{\mathrm{ws}}=\left(1.4 a_{\mathrm{w}, \mathrm{x}}^{2}+1.4 a_{\mathrm{w}, \mathrm{y}}^{2}+a_{\mathrm{w}, \mathrm{z}}^{2}\right)^{1 / 2}
$$

The root-sums-of-quads $\left(a_{\mathrm{wq}}\right)$ of the r.m.q. values for each machine or vehicle was calculated as:

$$
a_{\mathrm{wq}}=\left(1.4 a_{\mathrm{w}, \mathrm{x}}^{4}+1.4 a_{\mathrm{w}, \mathrm{y}}^{4}+a_{\mathrm{w}, \mathrm{z}}^{4}\right)^{1 / 4}
$$

For each operator, questionnaire data, information obtained by interviewing employees and employers, and company records were used to estimate daily and weekly exposure to WBV expressed in driving hours. In addition, samples of driving activities were monitored by a digital chronometer. Details of the sampling method to estimate the actual duration of vibration exposure during a typical workday are reported elsewhere ${ }^{17)}$.

Daily vibration exposure was expressed in terms of 8-h energy-equivalent frequency-weighted r.m.s. acceleration magnitude $(A(8))$ according to the EU Directive on mechanical vibration ${ }^{7)}$ :

$$
\left.A(8)=\left(\sum a_{\mathrm{wi}(\mathrm{rms})}\right)^{2} \cdot \mathrm{t}_{\mathrm{di}} / T_{(8)}\right)^{1 / 2} \quad\left(\mathrm{~ms}^{-2} \text { r.m.s. }\right)
$$

where $a_{\mathrm{wi}(\mathrm{rms})}$ is the weighted r.m.s. acceleration of vehicle $i$, $t_{\mathrm{di}}$ is daily driving hours on vehicle $i$, and $T_{(8)}$ is a reference duration of $8 \mathrm{~h}$.

In Eq. (3), $a_{\text {wi(rms) }}$ was included as either $a_{\mathrm{ws}}$ (Eq. 1), $\left(A(8)_{\text {sum }}\right)$, or the highest value of the frequency-weighted r.m.s. accelerations determined on three orthogonal axes, $\left(A(8)_{\max }\right)$, as required by the EU Directive ${ }^{7)}$.

Daily vibration exposure was also expressed in terms of vibration dose value (VDV):

$$
\mathrm{VDV}=a_{\mathrm{wi}(\mathrm{rmq})} \cdot\left(t_{\mathrm{di}} \cdot 60.60\right)^{1 / 4} \quad\left(\mathrm{~ms}^{-1.75}\right)
$$

where $a_{\mathrm{wi}(\mathrm{rmq})}$ is the weighted r.m.q. acceleration of vehicle $i$, and $t_{\mathrm{di}}$ is daily driving hours on vehicle $i$.

In Eq. (4), $a_{\mathrm{wi}(\mathrm{rmq})}$ was included as either $a_{\mathrm{wq}}$ (Eq. 2), $\left(\mathrm{VDV}_{\text {sum }}\right)$, or the highest value of the frequency-weighted r.m.q. accelerations determined on three orthogonal axes, $\left(\mathrm{VDV}_{\max }\right)$, as required by the EU Directive ${ }^{7)}$.

\section{Physical and psychosocial load factors}

A combined approach consisting of both direct observation of working conditions and the subject's self-assessment during the interview was used to evaluate the physical load in the professional drivers. Photographs and videos were taken at the workplace to analyse drivers' postures during a working day.

A perceived physical work load index was calculated from eleven questions including standing and walking at work, prolonged sitting other than when driving, bending forward, twisting, driving with back bent forward or twisted, digging and shoveling, working with arms raised and hand above shoulder, lifting loads $>15 \mathrm{~kg}$, and lifting with trunk bent or twisted. Heavy physical work was graded by rating the frequency of manual activities on a 3-point response scale (e.g. lifting loads $>15 \mathrm{~kg}$ with trunk bent and twisted: "not at all", "1-10 times", "more than 10 times"). Awkward postures were graded by rating the duration of each posture on a 4-point time scale ("never", "less than $1 \mathrm{~h}$ ", " $1-2 \mathrm{~h}$ ", "more than $2 \mathrm{~h}$ "). A mean value of physical load variables over a typical working day was calculated for each subject. In the total sample, the average perceived physical load index was divided into quartiles (q) which were assumed to correspond to four grades of increasing physical load: 1st $q=$ mild load grade, 2nd $\mathrm{q}=$ moderate load grade, 3rd q=hard load grade, 4th q=very hard load grade.

A measure of perceived psychosocial work environment was derived from five questions concerning job decision (three questions), job support (one question), and job satisfaction (one question $)^{18)}$. Job decision and job support were measured on a 4-point scale ("often", "sometimes", "seldom", "never/almost never"), as well as job satisfaction ("very satisfied", "satisfied", "dissatisfied", "very dissatisfied"). The mean value of psychosocial load variables was calculated for each subject, and in the total sample the new measure of perceived psychosocial work environment was categorised into quartiles of increasing psychosocial load: 1st q=good work environment; 2nd q=reasonable work environment; 3rd q=a little poor work environment; 4th q=poor work environment.

\section{Data analysis}

The statistical analysis of data was performed with the Stata software, version 10.1 (Stata Corporation, 2008). Continuous variables were summarised with the mean as a measure of central tendency and the standard deviation (SD) as a measure of dispersion.

Comparisons between independent groups were made with the Kruskall Wallis one-way analysis of variance. Differences between categorical data cross-tabulated into contingency tables were tested by the $\chi^{2}$ statistic.

The associations between LBP (ordinal) outcomes and individual- and work-related risk factors were assessed by random-intercept ordered logistic regression analysis to account 
Table 2. Frequency-weighted root-mean-square (r.m.s.) acceleration magnitude $\left(a_{\mathrm{w}}\right)$ of whole-body vibration measured in the $x$-, $y$-, and $z$-directions on the seat of industrial machines and transport vehicles $\left(a_{\mathrm{w}, \mathrm{x}}, a_{\mathrm{w}, \mathrm{y}}, a_{\mathrm{w}, \mathrm{z}}\right)$

\begin{tabular}{|c|c|c|c|c|c|c|}
\hline \multirow{2}{*}{ Sector } & \multirow{2}{*}{ Machine/vehicle } & \multirow{2}{*}{$\begin{array}{l}\text { Number of } \\
\text { vehicles } \\
\text { measured }\end{array}$} & \multicolumn{4}{|c|}{ Frequency-weighted acceleration magnitude } \\
\hline & & & $\begin{array}{c}a_{\mathrm{w}, \mathrm{x}} \\
\left(\mathrm{ms}^{-2} \text { r.m.s. }\right)\end{array}$ & $\begin{array}{c}a_{\mathrm{w}, \mathrm{y}} \\
\left(\mathrm{ms}^{-2} \text { r.m.s. }\right)\end{array}$ & $\begin{array}{c}a_{\mathrm{w}, \mathrm{z}} \\
\left(\mathrm{ms}^{-2} \text { r.m.s. }\right)\end{array}$ & $\begin{array}{c}a_{\mathrm{ws}} \\
\left(\mathrm{ms}^{-2} \text { r.m.s. }\right)\end{array}$ \\
\hline Marble quarries & Wheel loader & 7 & $0.21(0.04)$ & $0.25(0.06)$ & $0.35(0.09)$ & $0.57(0.11)$ \\
\hline Marble quarries & Excavator & 4 & $0.24(0.10)$ & $0.20(0.10)$ & $0.52(0.11)$ & $0.69(0.19)$ \\
\hline Marble quarries & Rock crusher & 1 & $0.07(0.01)$ & $0.07(0.02)$ & $0.66(0.07)$ & $0.67(0.12)$ \\
\hline Marble quarries & Articulated dumper & 1 & $0.14(0.04)$ & $0.18(0.10)$ & $0.38(0.12)$ & $0.50(0.15)$ \\
\hline Marble quarries & Off-road car & 1 & $0.33(0.08)$ & $0.38(0.09)$ & $0.85(0.10)$ & $1.1(0.11)$ \\
\hline Marble laboratories & Mobile crane & 5 & $0.06(0.01)$ & $0.07(0.02)$ & $0.29(0.06)$ & $0.32(0.06)$ \\
\hline Marble laboratories & Fork-lift truck & 8 & $0.30(0.03)$ & $0.28(0.07)$ & $0.95(0.12)$ & $1.1(0.10)$ \\
\hline Paper mill & Fork-lift truck & 11 & $0.11(0.02)$ & $0.11(0.02)$ & $0.30(0.05)$ & $0.37(0.04)$ \\
\hline Dockyard & Fork-lift truck & 8 & $0.20(0.08)$ & $0.15(0.06)$ & $0.40(0.14)$ & $0.54(0.17)$ \\
\hline Dockyard & Track-type loader & 3 & $0.29(0.15)$ & $0.30(0.15)$ & $0.49(0.26)$ & $0.76(0.39)$ \\
\hline Dockyard & Freight-container tractor & 1 & $0.16(0.01)$ & $0.21(0.01)$ & $0.57(0.03)$ & $0.68(0.03)$ \\
\hline Public utilities & Garbage truck & 5 & $0.10(0.02)$ & $0.10(0.02)$ & $0.24(0.03)$ & $0.31(0.03)$ \\
\hline Public utilities & Garbage compactor & 1 & $0.08(0.02)$ & $0.12(0.06)$ & $0.21(0.02)$ & $0.29(0.05)$ \\
\hline Public transport & Bus & 12 & $0.07(0.02)$ & $0.09(0.04)$ & $0.30(0.09)$ & $0.34(0.10)$ \\
\hline
\end{tabular}

The vibration total value of frequency-weighted r.m.s. accelerations $\left(a_{\mathrm{ws}}\right)$ is calculated according to International Standard ISO 2631-1 (1997). Data are given as means (SD).

for the within-subject dependency of the observations over time (gllamm procedure in Stata) ${ }^{19}$. Proportional odds ratios (ORs) and $95 \%$ confidence intervals $(95 \% \mathrm{CI})$ were estimated from the logistic regression coefficients and their standard errors. The assumption of proportional odds ratios of the predictor variables across response categories was checked with the Stata program gologit2.

Random-intercept ordinal logistic regression analysis was performed with a transition model, in which the outcome variable for subject $i$ at time-point $t\left(\mathrm{Y}_{i t}\right)$ was related to the value(s) of independent variable(s) $k$ for subject $i$ at timepoint $t-1\left(\mathrm{X}_{i k t-1}\right)$, and to the value of the outcome variable $\mathrm{Y}$ for subject $i$ at time-point $t-1\left(\mathrm{Y}_{i t-1}\right)$, i.e. the values of the predictors and the outcome at one measurement earlier. It is assumed that a transition model (also called autoregressive or Markov model) takes into account the temporal sequence of cause and effect and 'captures' the longitudinal part of the relationship ${ }^{20)}$.

Both exposure variables and confounding factors entered the logistic model as time-dependent categorical covariates, except for age at entry which was included as a time-independent continuous variable. All models included a linear term for time effect. Interactions between covariates were assessed by adding appropriate product terms to the logistic models. The significance of additional variables in the models was tested by the likelihood ratio (LR) chi-square statistic. The same statistic was used to test for trend $\left(\chi^{2}, 1\right.$ degree-of-freedom, $d f$ ) assigning the means of the $\log$ of the individual vibration exposures as scores for the exposure categories. The magnitude of the LR statistic was used to assess the 'importance', in statistical terms, of the alternative measures of daily vibration exposure for the prediction of the outcome.

\section{Results}

Vibration measurements

Table 2 reports the mean (SD) values of the frequency- weighted r.m.s. accelerations measured at the driver-seat interfaces on the machines and vehicles used by the professional drivers. The $z$-axis (vertical) weighted acceleration was the dominant directional component of vibration measured in most of the machines and vehicles. In marble quarries, the vibration total value $\left(a_{\mathrm{ws}}\right)$ of the weighted r.m.s. accelerations averaged 0.57 to $0.69 \mathrm{~ms}^{-2}$ r.m.s. in earth moving machines, and 0.5 to $1.1 \mathrm{~ms}^{-2}$ r.m.s. in transport vehicles. The lower $a_{\mathrm{ws}}$ values were measured on garbage machines $\left(0.29-0.31 \mathrm{~ms}^{-2}\right.$ r.m.s.), on mobile cranes used in marble laboratories $\left(0.32 \mathrm{~ms}^{-2}\right.$ r.m.s. $)$, and on buses $\left(0.34 \mathrm{~ms}^{-2}\right.$ r.m.s.). The average $a_{\mathrm{ws}}$ measured on the fork-lift trucks used in marble laboratories $\left(1.1 \mathrm{~ms}^{-2}\right.$ r.m.s.) was two to three times greater than those measured on the fork-lift trucks driven in dockyards $\left(0.54 \mathrm{~ms}^{-2}\right.$ r.m.s. $)$ and paper mills $\left(0.37 \mathrm{~ms}^{-2}\right.$ r.m.s.). This finding may be ascribed to differences in vehicle design and power, items to be lifted, operating conditions, and seat quality between the fork-lift trucks used in the various industries.

To evaluate the impulsiveness of WBV generated by the machines and vehicles driven by our workers, the crest factor (i.e. the ratio of the maximum istantaneous peak value of the frequency-weighted acceleration signal to its r.m.s. value) was calculated. According to ISO 2631-16), a crest factor $>9$ suggests that vibration may contain shocks or transients. In this study, the crest factors varied from 5.1 to 12.5 for earthmoving machines, 5.9 to 9.8 for fork-lift trucks, 3.5 to 5 for garbage machines, and 3 to 4 for buses.

\section{Characteristics of the driver groups}

At the initial survey, the three driver groups were well comparable for several characteristics such as age, body mass index, drinking habit, marital status, education, physical activity, and annual car driving (Table 3). Current smokers were more prevalent among fork-lift truck drivers (Group B). Seniority in current job was greater in the drivers of earthmoving machines (Group A), while previous jobs with WBV exposure were more frequent in the drivers employed in pub- 
Table 3. Individual characteristics, daily vibration exposure, physical and psychosocial risk factors in the professional drivers with no low back pain in the previous 12 months at baseline $(n=202)$

\begin{tabular}{|c|c|c|c|c|}
\hline & \multicolumn{4}{|c|}{ Drivers } \\
\hline & $\begin{array}{c}\text { Group A } \\
(\mathrm{n}=49)\end{array}$ & $\begin{array}{c}\text { Group B } \\
(\mathrm{n}=67)\end{array}$ & $\begin{array}{c}\text { Group C } \\
(\mathrm{n}=86)\end{array}$ & $\begin{array}{l}\text { Total sample } \\
\quad(\mathrm{n}=202)\end{array}$ \\
\hline Age (yr) & $41.3(9.9)$ & $40.1(9.9)$ & $41.0(8.3)$ & $40.8(9.2)$ \\
\hline Height $(\mathrm{cm})$ & $176(7.2)$ & $176(7.2)$ & $176(7.2)$ & $176(7.2)$ \\
\hline Weight (kg) & $80.6(11.1)$ & $79.4(14.8)$ & $81.6(10.5)$ & $80.6(12.2)$ \\
\hline BMI $\left(\mathrm{kg} / \mathrm{m}^{2}\right)$ & $26.1(3.3)$ & $25.7(4.5)$ & $26.4(3.0)$ & $26.1(3.6)$ \\
\hline $\begin{array}{r}\text { never } \\
\text { ex-smokers } \\
\text { current smokers }\end{array}$ & $\begin{array}{l}19(38.8) \\
13(26.5) \\
17(34.7)\end{array}$ & $\begin{array}{r}24(35.8) \\
9(13.4) \\
34(50.8)\end{array}$ & $\begin{array}{r}47(54.7) \\
17(19.8) \\
22(25.6)^{\mathrm{a}}\end{array}$ & $\begin{array}{l}90(44.6) \\
39(19.3) \\
73(36.1)\end{array}$ \\
\hline Drinking (units/wk) & $\begin{array}{r}18(36.7) \\
24(14.3) \\
7(14.3)\end{array}$ & $\begin{array}{l}23(34.3) \\
30(44.8) \\
14(20.9)\end{array}$ & $\begin{array}{l}41(47.7) \\
29(33.7) \\
16(18.6)\end{array}$ & $\begin{array}{l}82(40.6) \\
83(41.1) \\
37(18.3)\end{array}$ \\
\hline Married & $37(75.5)$ & $38(56.7)$ & $55(64.0)$ & $130(64.4)$ \\
\hline $\begin{array}{r}\leq 6 \mathrm{yr} \\
7-12 \mathrm{yr} \\
>12 \mathrm{yr}\end{array}$ & $\begin{array}{r}5(10.2) \\
31(63.3) \\
13(26.5)\end{array}$ & $\begin{array}{r}5(7.5) \\
43(64.2) \\
19(28.4)\end{array}$ & $\begin{array}{r}4(4.7) \\
56(65.1) \\
26(30.2)\end{array}$ & $\begin{array}{r}14(6.9) \\
130(64.4) \\
58(28.7)\end{array}$ \\
\hline $\begin{array}{l}\text { Physical activity: } \\
\qquad \begin{array}{r}\text { never/almost never } \\
1-2 \text { per wk } \\
\geq 3 \text { per wk }\end{array}\end{array}$ & $\begin{array}{r}28(57.2) \\
13(26.5) \\
8(16.3)\end{array}$ & $\begin{array}{l}39(58.2) \\
15(22.4) \\
13(19.4)\end{array}$ & $\begin{array}{l}46(53.5) \\
26(30.2) \\
14(16.3)\end{array}$ & $\begin{array}{r}113(56.0) \\
54(26.7) \\
35(17.3)\end{array}$ \\
\hline $\begin{array}{r}<8,000 \\
8-24,000 \\
>24,000\end{array}$ & $\begin{array}{r}13(26.5) \\
32(65.3) \\
4(8.2)\end{array}$ & $\begin{array}{l}19(28.4) \\
38(56.7) \\
10(14.9)\end{array}$ & $\begin{array}{r}29(33.7) \\
51(59.3) \\
6(7.0)\end{array}$ & $\begin{array}{r}61(30.2) \\
121(59.9) \\
20(9.9)\end{array}$ \\
\hline $\begin{array}{l}\text { Previous jobs with } \\
\text { WBV exposure }\end{array}$ & $11(22.5)$ & $16(23.9)$ & $53(61.3)^{\mathrm{b}}$ & $80(39.6)$ \\
\hline $\begin{array}{l}\text { Previous job with } \\
\text { heavy physical load }\end{array}$ & $10(20.4)$ & $18(26.9)$ & $10(11.6)$ & $38(18.8)$ \\
\hline Job seniority (yr) & $14.4(11.1)$ & $11.3(8.9)$ & $9.8(8.3)^{\mathrm{d}}$ & $11.4(9.4)$ \\
\hline Daily driving time (h) & $5.6(2.8)$ & $5.2(2.3)$ & $6.06(0.6)^{\mathrm{c}}$ & $5.7(1.9)$ \\
\hline$A(8)_{\text {sum }}\left(\mathrm{ms}^{-2}\right.$ r.m.s. $)$ & $0.55(0.18)$ & $0.43(0.15)$ & $0.32(0.05)^{\mathrm{d}}$ & $0.41(0.16)$ \\
\hline$A(8)_{\max }\left(\mathrm{ms}^{-2}\right.$ r.m.s. $)$ & $0.37(0.13)$ & $0.34(0.14)$ & $0.26(0.03)^{\mathrm{d}}$ & $0.32(0.11)$ \\
\hline $\mathrm{VDV}_{\text {sum }}\left(\mathrm{ms}^{-1.75}\right)$ & $11.4(3.3)$ & $11.2(4.1)$ & $6.6(1.2)^{\mathrm{d}}$ & $9.3(3.8)$ \\
\hline $\mathrm{VDV}_{\max }\left(\mathrm{ms}^{-1.75}\right)$ & $10.0(3.3)$ & $10.8(4.1)$ & $5.9(0.5)^{\mathrm{d}}$ & $8.5(3.7)$ \\
\hline $\begin{array}{r}\text { Perceived physical work load: } \\
\text { mild } \\
\text { moderate } \\
\text { hard } \\
\text { very hard }\end{array}$ & $\begin{array}{r}5(10.2) \\
13(26.5) \\
16(32.7) \\
15(30.6)\end{array}$ & $\begin{array}{r}8(11.9) \\
9(13.4) \\
21(31.4) \\
29(43.3)\end{array}$ & $\begin{array}{r}39(45.4) \\
27(31.4) \\
14(16.3) \\
6(6.9)^{b}\end{array}$ & $\begin{array}{l}52(25.7) \\
49(24.3) \\
51(25.3) \\
50(24.7)\end{array}$ \\
\hline $\begin{array}{l}\text { Perceived psychosocial } \\
\text { work environment: } \\
\text { good (score 5) } \\
\text { reasonable (score } 6-10) \\
\text { a little poor (score } 11-15) \\
\text { poor }(\text { score } 16-20)\end{array}$ & $\begin{array}{r}29(59.2) \\
13(26.5) \\
5(10.2) \\
2(4.1)\end{array}$ & $\begin{array}{r}23(34.3) \\
15(22.4) \\
21(31.3) \\
8(11.9)\end{array}$ & $\begin{array}{r}5(5.8) \\
15(17.4) \\
25(29.1) \\
41(47.7)^{\mathrm{b}}\end{array}$ & $\begin{array}{l}57(28.2) \\
43(21.3) \\
51(25.3) \\
51(25.3)\end{array}$ \\
\hline
\end{tabular}

Data are given as means (SD) or numbers $(\%)$. See text for the definition of the measures of daily vibration exposure $(A(8), \mathrm{VDV})$.

$\chi^{2}$ test: ${ }^{\mathrm{a}} p<0.05 ;{ }^{\mathrm{b}} p<0.01$. Kruskal Wallis test: ${ }^{\mathrm{c}} p<0.05 ;{ }^{\mathrm{d}} p<0.01$.

lic utilities (Group C). Perceived physical work load was more severe in the drivers of Group A and B than in those of Group C $(p<0.01)$, while these latter experienced poor psy- chosocial work environment more frequently than the other two driver groups $(p<0.01)$.

Daily vibration exposure in terms of driving hours was, 
Table 4. Cumulative incidence of low back pain (LBP) outcomes over the follow up period in the professional drivers with no LBP in the previous 12 months at baseline

\begin{tabular}{|c|c|c|c|c|}
\hline \multirow[t]{2}{*}{ Outcome } & \multicolumn{4}{|c|}{ Drivers } \\
\hline & $\begin{array}{c}\text { Group A } \\
(\mathrm{n}=49)\end{array}$ & $\begin{array}{c}\text { Group B } \\
(\mathrm{n}=67)\end{array}$ & $\begin{array}{c}\text { Group C } \\
(\mathrm{n}=86)\end{array}$ & $\begin{array}{l}\text { Total sample } \\
\quad(\mathrm{n}=202)\end{array}$ \\
\hline LBP in the previous 12 months & $23(46.9)$ & $25(37.3)$ & $30(34.9)$ & $78(38.6)$ \\
\hline \multicolumn{5}{|l|}{$\begin{array}{l}\text { Duration of LBP in the previous } 12 \\
\text { months (days) }\end{array}$} \\
\hline 0 & $26(53.1)$ & $42(62.7)$ & $56(65.1)$ & $124(61.4)$ \\
\hline $1-6$ & $14(28.5)$ & $15(22.4)$ & $20(23.3)$ & $49(24.2)$ \\
\hline$\geq 7$ & $9(18.4)$ & $10(14.9)$ & $10(11.6)$ & $29(14.4)$ \\
\hline \multicolumn{5}{|l|}{$\begin{array}{l}\text { Pain intensity in the previous } 12 \\
\text { months (numerical scale score) }\end{array}$} \\
\hline 0 & $26(53.1)$ & $42(62.7)$ & $56(65.1)$ & $124(61.4)$ \\
\hline $1-5$ & $13(26.5)$ & $12(17.9)$ & $19(22.1)$ & $44(21.8)$ \\
\hline $6-10$ & $10(20.4)$ & $13(19.4)$ & $11(12.8)$ & $34(16.8)$ \\
\hline \multicolumn{5}{|l|}{$\begin{array}{l}\text { Disability due to the last episode of } \\
\text { LBP (Roland \& Morris disability } \\
\text { scale score) }\end{array}$} \\
\hline $\begin{array}{ll}2 & 0\end{array}$ & $27(55.1)$ & $44(65.7)$ & $61(70.9)$ & $132(65.3)$ \\
\hline $1-12$ & $14(28.6)$ & $9(13.4)$ & $18(20.9)$ & $41(20.3)$ \\
\hline $13-24$ & $8(16.3)$ & $14(20.9)$ & $7(8.1)$ & $29(14.4)$ \\
\hline
\end{tabular}

Data are given as numbers $(\%)$.

on average, higher in Group $\mathrm{C}$ than in Group B $(p=0.03)$, but the estimated $A(8)$ and VDV (both highest axis and summation over axes) were greater in Groups $\mathrm{A}$ and $\mathrm{B}$ than in Group C $(0.001<p<0.05)$. Over the follow-up period, there were no significant changes in the mean values of daily exposure duration, $A(8)$ and VDV, in all driver groups (results not shown). However, when the measures of daily vibration exposure were divided into tertiles, about $72 \%$ of the drivers showed no change in their exposure category over the followup period, while $10 \%$ moved down to a lower tertile category (i.e. reduced exposure), and $18 \%$ moved up to a higher tertile category (i.e. increased exposure).

\section{Incidence of LBP outcomes}

In the entire study population, the cumulative incidence of LBP over the follow up period was $38.6 \%$ (Table 4). The incidence of high pain intensity (NRS score $>5$ ) and severe disability (R\&M scale score $>12$ ) was 16.8 and $14.4 \%$, respectively. Although the incidences of duration of LBP, pain intensity and disability in the lower back were higher in Group A and B than in Group C, the differences were not significant ( $p=0.07$ to 0.68 ).

\section{LBP outcomes and individual- and work-related risk factors}

In the entire sample, the risk of LBP outcomes tended to increase with age, although not significantly (Table 5). After adjusting for covariates, there were no associations between LBP outcomes and several individual characteristics (e.g. smoking and drinking habit, education, marital status). Over the follow-up period, the incidence of LBP outcomes was higher in the drivers of earth-moving machines and forklift trucks than in those employed in public utilities, but the increase in the proportional ORs was not significant. Previous jobs with exposure to either WBV or heavy physical demands were not associated with LBP outcomes over time. Body mass index was inversely related to the duration of LBP and pain intensity in the lower back $(p<0.05)$, while regular physical activity was protective against disability $(p=0.014)$. There was a strong association between all forms of LBP and perceived physical load at work: the magnitude of the proportional ORs for the incidence of LBP increased significantly with the increase of the severity of physical demands. In the driver population, perceived psychosocial work environment and psychosomatic symptoms were not associated with the development of LBP over the follow-up period.

\section{LBP outcomes and measures of daily vibration exposure}

In the entire study population, there were significant differences in the crude distribution of the cumulative incidence of LBP outcomes across the measures of daily vibration exposure divided into tertiles, mainly for $\operatorname{VDV}_{\text {sum }}$ (Table 6). After adjustment for individual characteristics, physical and psychosocial risk factors, psychosomatic symptoms, survey time, and LBP outcomes at one time earlier, random-intercept logistic regression analysis (transition model) showed significant associations between the various forms of LBP outcomes and nearly all measures of daily vibration exposure, except for $A(8)_{\max }$ (Table 7). A statistical test revealed that the final models did not violate the assumption of proportional odds of the predictors across all cut-off points of the response variables (mild or severe LBP vs no LBP, severe LBP $v s$ mild or no LBP). Test for trends and the pattern of the proportional ORs showed that VDV tended to give better predictions for LBP outcomes than $A(8)$, for both measures derived from the highest axis $\left(\mathrm{VDV}_{\max } v s A(8)_{\max }\right)$ and measures calculated from summation over axes $\left(\operatorname{VDV}_{\text {sum }} v s A(8)_{\text {sum }}\right)$. Duration of daily exposure to WBV was also associated with LBP outcomes, although to a lesser extent than $\mathrm{VDV}_{\text {sum }}$ for duration of LBP and pain intensity. There was evidence for a strong influence of prior episodes of low back complaints on the 
Table 5. Association between LBP (ordinal) outcomes over the follow up period (duration of LBP, pain intensity, disability) and individual- and work-related factors in the professional drivers with no LBP at baseline ( $\mathrm{n}=\mathbf{2 0 2}$ )

Proportional odds ratios (OR)* and $95 \%$ confidence intervals $(95 \% \mathrm{CI})$ are estimated by randomintercept ordered logistic regression (transition model) to account for the within-subject correlation between repeated measures. The likelihood ratio (LR) statistic for the predictors is shown.

\begin{tabular}{|c|c|c|c|}
\hline \multirow[t]{2}{*}{ Factors } & Duration of LBP & Pain intensity & Disability \\
\hline & $\mathrm{OR}(95 \% \mathrm{CI})$ & OR $(95 \% \mathrm{CI})$ & OR $(95 \% \mathrm{CI})$ \\
\hline \multicolumn{4}{|l|}{ Age (yr) } \\
\hline$<35$ & $1.0(-)$ & $1.0(-)$ & $1.0(-)$ \\
\hline $35-45$ & $0.88(0.39-1.97)$ & $1.13(0.24-5.24)$ & $1.17(0.33-4.14)$ \\
\hline$>45$ & $1.37(0.60-3.15)$ & $1.85(0.40-8.64)$ & $1.72(0.45-6.52)$ \\
\hline LR statistic $\left(\chi^{2}, 2 d f\right)$ & $1.29(p=0.53)$ & $0.89(p=0.64)$ & $0.76(p=0.68)$ \\
\hline \multicolumn{4}{|c|}{ Driving occupation } \\
\hline Group C & $1.0(-)$ & $1.0(-)$ & $1.0(-)$ \\
\hline Group B & $1.18(0.53-2.63)$ & $1.87(0.37-9.52)$ & $3.00(0.57-15.9)$ \\
\hline Group A & $1.44(0.61-3.42)$ & $2.70(0.42-17.5)$ & $3.51(0.54-22.6)$ \\
\hline LR statistic $\left(\chi^{2}, 2 d f\right)$ & $0.76(p=0.68)$ & $1.52(p=0.47)$ & $3.31(p=0.19)$ \\
\hline \multicolumn{4}{|c|}{$\operatorname{BMI}\left(\mathrm{kg} / \mathrm{m}^{2}\right)$} \\
\hline$<24$ & $1.0(-)$ & $1.0(-)$ & $1.0(-)$ \\
\hline $24-27$ & $0.62(0.29-1.33)$ & $0.49(0.18-1.30)$ & $0.40(0.10-1.56)$ \\
\hline$>27$ & $0.35(0.15-0.81)$ & $0.27(0.09-0.82)$ & $0.38(0.10-1.42)$ \\
\hline LR statistic $\left(\chi^{2}, 2 d f\right)$ & $9.50(p=0.009)$ & $6.34(p=0.042)$ & $2.96(p=0.23)$ \\
\hline \multicolumn{4}{|l|}{ Smoking } \\
\hline no smoking & $1.0(-)$ & $1.0(-)$ & $1.0(-)$ \\
\hline ex-smoker & $0.65(0.27-1.56)$ & $1.20(0.21-6.70)$ & $1.03(0.22-4.78)$ \\
\hline current smoker & $1.18(0.59-2.36)$ & $1.89(0.47-7.55)$ & $1.55(0.46-5.23)$ \\
\hline LR statistic $\left(\chi^{2}, 2 d f\right)$ & $1.71(p=0.42)$ & $0.92(p=0.63)$ & $0.59(p=0.74)$ \\
\hline \multicolumn{4}{|c|}{ Drinking (units/wk) } \\
\hline 然 & $1.0(-)$ & $1.0(-)$ & $1.0(-)$ \\
\hline $1-3$ & $0.75(0.38-1.50)$ & $1.0(0.29-3.48)$ & $1.32(0.42-4.17)$ \\
\hline $4-6$ & $0.74(0.30-1.87)$ & $0.83(0.15-4.50)$ & $1.05(0.23-4.78)$ \\
\hline LR statistic $\left(\chi^{2}, 2 d f\right)$ & $0.76(p=0.68)$ & $0.05(p=0.97)$ & $0.25(p=0.88)$ \\
\hline \multicolumn{4}{|c|}{ 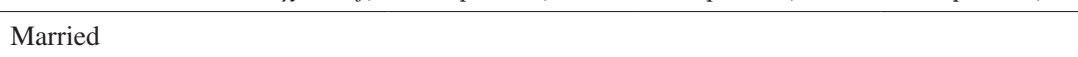 } \\
\hline no & $1.0(-)$ & $1.0(-)$ & $1.0(-)$ \\
\hline yes & $0.98(0.47-2.04)$ & $1.40(0.31-6.28)$ & $0.84(0.26-2.76)$ \\
\hline LR statistic $\left(\chi^{2}, 1 d f\right)$ & $0.01(p=0.96)$ & $0.21(p=0.65)$ & $0.08(p=0.79)$ \\
\hline \multicolumn{4}{|c|}{ Education (yr) } \\
\hline$\leq 6$ & $1.0(-)$ & $1.0(-)$ & $1.0(-)$ \\
\hline $7-12$ & $1.23(0.30-4.98)$ & $0.91(0.20-4.17)$ & $0.66(0.05-9.28)$ \\
\hline$>12$ & $1.36(0.32-5.86)$ & $0.69(0.02-35.1)$ & $0.90(0.06-14.4)$ \\
\hline LR statistic $\left(\chi^{2}, 2 d f\right)$ & $0.45(p=0.80)$ & $1.30(p=0.52)$ & $0.32(p=0.85)$ \\
\hline \multicolumn{4}{|c|}{ Physical activity } \\
\hline never/almost never & $1.0(-)$ & $1.0(-)$ & $1.0(-)$ \\
\hline $1-2$ per wk & $1.38(0.63-2.99)$ & $1.30(0.62-2.73)$ & $1.36(0.63-2.94)$ \\
\hline$\geq 3$ per wk & $0.45(0.15-1.31)$ & $0.46(0.18-1.22)$ & $0.28(0.09-0.83)$ \\
\hline LR statistic $\left(\chi^{2}, 2 d f\right)$ & $4.78(p=0.09)$ & $4.20(p=0.12)$ & $8.56(p=0.014)$ \\
\hline \multicolumn{4}{|l|}{ Car driving $(\mathrm{km} / \mathrm{yr})$} \\
\hline$<8,000$ & $1.0(-)$ & $1.0(-)$ & $1.0(-)$ \\
\hline $8-24,000$ & $1.39(0.64-3.03)$ & $1.44(0.39-5.27)$ & $1.16(0.33-4.14)$ \\
\hline$>24,000$ & $1.13(0.55-2.31)$ & $1.08(0.30-3.94)$ & $0.87(0.27-2.88)$ \\
\hline LR statistic $\left(\chi^{2}, 2 d f\right)$ & $0.11(p=0.95)$ & $0.15(p=0.93)$ & $0.05(p=0.97)$ \\
\hline \multicolumn{4}{|c|}{ Previous jobs with } \\
\hline \multirow{3}{*}{$\begin{array}{l}\text { nore } \\
\text { yes } \\
\text { LR statistic }\left(\chi^{2}, 1 d f\right)\end{array}$} & $1.0(-)$ & $1.0(-)$ & $1.0(-)$ \\
\hline & $0.93(0.47-1.84)$ & $0.98(0.31-3.16)$ & $0.63(0.23-1.75)$ \\
\hline & $0.04(p=0.84)$ & $0.09(p=0.76)$ & $1.04(p=0.31)$ \\
\hline
\end{tabular}


Table 5. (continued)

\begin{tabular}{|c|c|c|c|}
\hline \multirow[t]{2}{*}{ Factors } & Duration of LBP & Pain intensity & Disability \\
\hline & $\mathrm{OR}(95 \% \mathrm{CI})$ & OR $(95 \% \mathrm{CI})$ & OR $(95 \% \mathrm{CI})$ \\
\hline \multicolumn{4}{|l|}{ Perceived physical work load } \\
\hline mild & $1.0(-)$ & $1.0(-)$ & $1.0(-)$ \\
\hline moderate & $1.44(0.57-3.68)$ & $1.58(0.63-3.97)$ & $1.64(0.62-4.32)$ \\
\hline hard & $3.21(1.28-8.09)$ & $2.73(1.12-6.70)$ & $2.97(1.16-7.57)$ \\
\hline very hard & $3.13(1.22-7.99)$ & $2.71(1.07-6.84)$ & $3.93(1.47-10.5)$ \\
\hline LR statistic $\left(\chi^{2}, 3 d f\right)$ & $9.64(p=0.022)$ & $8.54(p=0.035)$ & $9.92(p=0.019)$ \\
\hline \multicolumn{4}{|l|}{$\begin{array}{l}\text { Perceived psychosocial } \\
\text { work environment }\end{array}$} \\
\hline good & $1.0(-)$ & $1.0(-)$ & $1.0(-)$ \\
\hline reasonable & $0.87(0.45-1.65)$ & $0.79(0.41-1.52)$ & $0.68(0.35-1.32)$ \\
\hline a little poor & $1.28(0.63-2.59)$ & $1.41(0.70-2.82)$ & $0.75(0.36-1.55)$ \\
\hline poor & $1.31(0.65-2.65)$ & $1.29(0.64-2.59)$ & $1.16(0.57-2.36)$ \\
\hline LR statistic $\left(\chi^{2}, 3 d f\right)$ & $3.17(p=0.37)$ & $3.78(p=0.29)$ & $2.89(p=0.41)$ \\
\hline \multicolumn{4}{|l|}{$\begin{array}{l}\text { Psychosomatic symptoms } \\
\text { in the previous } 7 \text { days }\end{array}$} \\
\hline 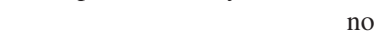 & $1.0(-)$ & $1.0(-)$ & $1.0(-)$ \\
\hline yes & $1.92(0.97-3.81)$ & $2.12(0.78-5.79)$ & $1.67(0.65-4.27)$ \\
\hline LR statistic $\left(\chi^{2}, 1 d f\right)$ & $5.0(p=0.08)$ & $3.77(p=0.15)$ & $2.78(p=0.10)$ \\
\hline
\end{tabular}

*Adjusted by age at entry, survey time, and LBP (ordinal) outcomes at one time earlier.

Table 6. Cumulative incidence of LBP (ordinal) outcomes over the follow-up period (duration of LBP, pain intensity, disability) by measures of daily vibration exposure in the professional drivers with no LBP in the previous 12 months at baseline (n=202)

\begin{tabular}{|c|c|c|c|c|c|c|c|c|c|}
\hline \multirow{3}{*}{$\begin{array}{l}\text { Measures of daily } \\
\text { vibration exposure }\end{array}$} & \multicolumn{3}{|c|}{ Duration of LBP $(\mathrm{d} / \mathrm{yr})$} & \multicolumn{3}{|c|}{ Pain intensity score } & \multicolumn{3}{|c|}{ Disability score } \\
\hline & 0 & $1-6$ & $\geq 7$ & 0 & $1-5$ & $6-10$ & 0 & $1-12$ & $13-24$ \\
\hline & $\mathrm{N}(\%)$ & $\mathrm{N}(\%)$ & $\mathrm{N}(\%)$ & $\mathrm{N}(\%)$ & $\mathrm{N}(\%)$ & $\mathrm{N}(\%)$ & $\mathrm{N}(\%)$ & $\mathrm{N}(\%)$ & $\mathrm{N}(\%)$ \\
\hline \multicolumn{10}{|l|}{ Daily driving time (h) } \\
\hline$<5$ & $46(67.7)$ & $13(19.1)$ & $9(13.2)$ & $46(67.7)$ & $13(19.1)$ & $9(13.2)$ & $49(72.1)$ & 14 (20.6) & $5(7.4)$ \\
\hline $5-6$ & $42(57.5)$ & $22(30.1)$ & $9(12.3)$ & $42(57.5)$ & $19(26.0)$ & $12(16.4)$ & $48(65.8)$ & $16(21.9)$ & $9(12.3)$ \\
\hline$>6$ & $36(59.0)$ & $14(23.0)$ & $11(18.0)$ & $36(59.0)$ & $12(19.7)$ & $13(21.3)$ & $35(57.4)$ & $11(18.0)$ & $15(24.6)$ \\
\hline \multicolumn{10}{|l|}{$A(8)_{\text {sum }}\left(\mathrm{ms}^{-2}\right.$ r.m.s. $)$} \\
\hline$<0.3$ & 45 (64.3) & $16(22.9)$ & $9(12.9)$ & $45(64.3)$ & $18(25.7)$ & $7(10.0)$ & $52(74.3)$ & $14(20.0)$ & $4(5.7)$ \\
\hline $0.3-0.4$ & $31(45.6)$ & $24(35.3)$ & $13(19.1)$ & $21(45.6)$ & $19(27.9)$ & $18(26.5)$ & $32(47.1)$ & $18(26.5)$ & $18(26.5)$ \\
\hline$>0.4$ & $48(75.0)$ & $9(14.1)$ & $7(10.9)$ & $48(75.0)$ & $7(10.9)$ & $9(14.1)^{\mathrm{c}}$ & $48(75.0)$ & $9(14.1)$ & $7(10.9)^{\mathrm{c}}$ \\
\hline \multicolumn{10}{|l|}{$A(8)_{\max }\left(\mathrm{ms}^{-2}\right.$ r.m.s. $)$} \\
\hline$<0.25$ & $36(53.7)$ & $20(29.9)$ & $11(16.4)$ & $36(53.7)$ & $18(26.9)$ & $13(19.4)$ & $40(59.7)$ & $17(25.4)$ & $10(14.9)$ \\
\hline $0.25-0.30$ & $41(56.9)$ & $20(27.8)$ & $11(15.3)$ & $41(56.9)$ & $20(27.8)$ & $11(15.3)$ & $45(62.5)$ & $16(22.2)$ & $11(15.3)$ \\
\hline$>0.30$ & $47(74.6)$ & $9(14.3)$ & $7(11.1)$ & $47(74.6)$ & $6(9.5)$ & $10(15.9)$ & $47(74.6)$ & $8(12.7)$ & $8(12.7)$ \\
\hline \multicolumn{10}{|l|}{$\operatorname{VDV}_{\text {sum }}\left(\mathrm{ms}^{-1.75}\right)$} \\
\hline$<6.5$ & $48(72.7)$ & $11(16.7)$ & $7(10.6)$ & $48(72.7)$ & $13(19.7)$ & $5(7.6)$ & $53(80.3)$ & $9(13.6)$ & $4(6.1)$ \\
\hline $6.5-10.5$ & $33(46.5)$ & $27(38.0)$ & $11(15.4)$ & $33(46.5)$ & $22(31.0)$ & $16(22.5)$ & $36(50.7)$ & $21(29.6)$ & $14(19.7)$ \\
\hline$>10.5$ & $43(66.2)$ & $11(16.9)$ & $11(16.9) \mathrm{b}$ & $43(66.2)$ & $9(13.9)$ & $13(20.0)^{\mathrm{b}}$ & $43(66.2)$ & $11(16.9)$ & $11(16.9)^{\mathrm{b}}$ \\
\hline \multicolumn{10}{|l|}{$\mathrm{VDV}_{\max }\left(\mathrm{ms}^{-1.75}\right)$} \\
\hline$<6.0$ & $46(69.7)$ & $13(19.7)$ & 7 (10.6) & 46 (69.7) & $14(21.2)$ & $6(9.1)$ & $51(77.3)$ & $11(16.7)$ & $4(6.1)$ \\
\hline $6.0-9.1$ & $36(49.3)$ & $24(32.9)$ & $13(17.8)$ & $36(49.3)$ & $21(28.8)$ & $16(21.9)$ & $39(53.4)$ & $19(26.0)$ & $15(20.6)$ \\
\hline$>9.1$ & $42(66.7)$ & $13(17.8)$ & $9(14.3)$ & $42(66.7)$ & $9(14.3)$ & $12(19.1)^{\mathrm{a}}$ & $42(66.7)$ & $11(17.5)$ & $10(15.9)^{\mathrm{a}}$ \\
\hline
\end{tabular}

Data are given as numbers (row percentages). See text for the definition of the measures of daily vibration exposure $\left(A(8)_{\text {sum }}, A(8)_{\max }, \mathrm{VDV}_{\text {sum }}\right.$, $\left.\mathrm{VDV}_{\max }\right)$.

${ }^{\mathrm{a}} p<0.05 ;{ }^{\mathrm{b}} p<0.01 ;{ }^{\mathrm{c}} p<0.005$.

occurrence of subsequent LBP outcomes (ORs 3.2 to 13.4 for prior duration of LBP, 3.3 to 5.3 for prior pain intensity, and 4.1 to 8.8 for prior disability, all $p$-values $<0.001$ ), (results not shown). There were no significant interactions between daily vibration exposure, physical load, and psychosocial environ- ment, and between these work-related risk factors and previous LBP when appropriate product terms were included in the transition models. 
Table 7. Association between LBP (ordinal) outcomes over the follow-up period (duration of LBP, pain intensity, disability) and alternative measures of daily vibration exposure in the professional drivers with no LBP in the previous 12 months at baseline $(n=202)$

Proportional odds ratios (OR)* and $95 \%$ confidence intervals $(95 \% \mathrm{CI})$ are estimated by randomintercept ordered logistic regression (transition model) to account for the within-subject correlation between repeated measures. The likelihood ratio (LR) statistics for the measures of daily vibration exposure are shown. See text for the definition of the measures of daily vibration exposure $\left(A(8)_{\text {sum }}\right.$, $\left.A(8)_{\max }, \mathrm{VDV}_{\text {sum }}, \mathrm{VDV}_{\max }\right)$.

\begin{tabular}{|c|c|c|c|}
\hline \multirow{2}{*}{$\begin{array}{l}\text { Models for the measures of } \\
\text { daily vibration exposure }\end{array}$} & Duration of LBP & Pain intensity & Disability \\
\hline & OR $(95 \% \mathrm{CI})$ & OR $(95 \% \mathrm{CI})$ & OR $(95 \% \mathrm{CI})$ \\
\hline \multicolumn{4}{|l|}{ Model 1: Daily driving time (h) } \\
\hline$<5$ & $1.0(-)$ & $1.0(-)$ & $1.0(-)$ \\
\hline $5-6$ & $1.28(0.62-2.61)$ & $1.46(0.55-3.88)$ & $2.12(0.65-6.94)$ \\
\hline$>6$ & $2.13(1.07-4.21)$ & $2.75(0.85-8.95)$ & $6.23(1.50-25.9)$ \\
\hline LR statistic $\left(\chi^{2}, 2 d f\right)$ & $5.28(p=0.071)$ & $6.05(p=0.049)$ & $14.7(p=0.0006)$ \\
\hline LR test for trend $\left(\chi^{2}, 1 d f\right)$ & $3.87(p=0.049)$ & $4.60(p=0.032)$ & $11.8(p=0.0006)$ \\
\hline \multicolumn{4}{|l|}{ Model 2: $A(8)_{\text {sum }}\left(\mathrm{ms}^{-2}\right.$ r.m.s. $)$} \\
\hline$<0.3$ & $1.0(-)$ & $1.0(-)$ & $1.0(-)$ \\
\hline $0.3-0.4$ & $2.32(1.22-4.44)$ & $2.38(1.24-4.55)$ & $4.08(1.31-12.7)$ \\
\hline$>0.4$ & $1.64(0.82-3.29)$ & $1.79(0.89-3.60)$ & $2.58(0.94-7.05)$ \\
\hline LR statistic $\left(\chi^{2}, 2 d f\right)$ & $8.88(p=0.012)$ & $9.72(p=0.008)$ & $18.5(p=0.0001)$ \\
\hline LR test for trend $\left(\chi^{2}, 1 d f\right)$ & $2.95(p=0.086)$ & $3.92(p=0.048)$ & $5.43(p=0.020)$ \\
\hline \multicolumn{4}{|l|}{ Model 3: $A(8)_{\max }\left(\mathrm{ms}^{-2}\right.$ r.m.s. $)$} \\
\hline$<0.25$ & $1.0(-)$ & $1.0(-)$ & $1.0(-)$ \\
\hline $0.25-0.30$ & $2.19(1.13-4.25)$ & $1.70(0.89-3.26)$ & $1.73(0.88-3.40)$ \\
\hline$>0.30$ & $1.58(0.82-3.03)$ & $1.51(0.79-2.86)$ & $1.56(0.81-3.00)$ \\
\hline LR statistic $\left(\chi^{2}, 2 d f\right)$ & $5.60(p=0.061)$ & $2.97(p=0.23)$ & $3.02(p=0.22)$ \\
\hline LR test for trend $\left(\chi^{2}, 1 d f\right)$ & $1.04(p=0.31)$ & $1.10(p=0.29)$ & $1.29(p=0.26)$ \\
\hline \multicolumn{4}{|l|}{ Model 4: $\mathrm{VDV}_{\text {sum }}\left(\mathrm{ms}^{-1.75}\right)$} \\
\hline$<6.5$ & $1.0(-)$ & $1.0(-)$ & $1.0(-)$ \\
\hline $6.5-10.5$ & $2.84(1.42-5.68)$ & $3.22(1.61-6.44)$ & $6.45(1.53-27.1)$ \\
\hline$>10.5$ & $2.70(1.27-5.71)$ & $3.05(1.43-6.50)$ & $5.74(1.27-25.9)$ \\
\hline LR statistic $\left(\chi^{2}, 2 d f\right)$ & $10.3(p=0.006)$ & $12.9(p=0.0016)$ & $16.5(p=0.0003)$ \\
\hline LR test for trend $\left(\chi^{2}, 1 d f\right)$ & $4.86(p=0.028)$ & $6.34(p=0.012)$ & $7.51(p=0.006)$ \\
\hline \multicolumn{4}{|l|}{ Model 5: $\mathrm{VDV}_{\max }\left(\mathrm{ms}^{-1.75}\right)$} \\
\hline$<6.0$ & $1.0(-)$ & $1.0(-)$ & $1.0(-)$ \\
\hline $6.0-9.1$ & $2.79(1.39-5.58)$ & $3.17(1.59-6.36)$ & $4.94(1.39-17.5)$ \\
\hline$>9.1$ & $2.44(1.16-5.15)$ & $2.77(1.31-5.88)$ & $4.14(1.12-15.3)$ \\
\hline LR statistic $\left(\chi^{2}, 2 d f\right)$ & $9.30(p=0.0095)$ & $11.9(p=0.0025)$ & $14.2(p=0.0008)$ \\
\hline LR test for trend $\left(\chi^{2}, 1 d f\right)$ & $2.61(p=0.11)$ & $3.47(p=0.06)$ & $4.16(p=0.041)$ \\
\hline
\end{tabular}

*Adjusted by individual characteristics, physical and psychosocial risk factors, psychosomatic symptoms, survey time, and LBP (ordinal) outcomes at one time earlier.

\section{Discussion}

The frequency-weighted acceleration magnitudes of vibration measured on the machines and vehicles of this survey are similar to those reported in recent and past investigations $1,3,8,21-26)$. Overall, the root-sums-of-squares of the r.m.s. accelerations $\left(a_{\mathrm{ws}}\right)$ and the root-sums-of-quads of the r.m.q. values $\left(a_{\mathrm{wq}}\right)$ measured on the vehicles of the various companies ranged 0.24 to 1.21 (mean 0.54 ) $\mathrm{ms}^{-2}$ r.m.s. and 0.44 to 1.69 (mean 0.76) $\mathrm{ms}^{-2}$ r.m.q., respectively. The most severe axis acceleration ranged 0.20 to 0.95 (mean 0.41 ) $\mathrm{ms}^{-2}$ r.m.s. and 0.41 to 1.48 (mean 0.70 ) $\mathrm{ms}^{-2}$ r.m.q.. Paired data comparison showed that the difference between multi-axis acceleration $\left(a_{\mathrm{ws}}\right.$ or $\left.a_{\mathrm{wq}}\right)$ and the most severe axis acceleration was highly sig- nificant $(p<0.001)$.

In this study, we have estimated daily vibration exposure $(A(8)$ and VDV) including in Eqs. (3) and (4) different measures of frequency-weighted acceleration magnitude $\left(a_{\mathrm{ws}}\right.$ and the highest r.m.s. acceleration to calculate $A(8)_{\text {sum }}$ and $A(8)_{\max }$, respectively; $a_{\mathrm{wq}}$ and the highest r.m.q. acceleration to calculate $\mathrm{VDV}_{\text {sum }}$ and $\mathrm{VDV}_{\text {max }}$, respectively). In each driver group of this study, $A(8)_{\text {sum }}$ and $\mathrm{VDV}_{\text {sum }}$ were significantly greater than $A(8)_{\max }$ and $\mathrm{VDV}_{\max }$, respectively $(p<0.001)$. Since most of the European countries have adopted $A(8)_{\max }$ as the basic indicator for the assessment of daily vibration exposure, it is a matter of concern that in the entire driver population $A(8)_{\max }$ showed the weakest associations with LBP outcomes compared with the other measures of daily exposure to WBV. 
Table 8. Distribution of the drivers according to the action values for daily vibration exposure established by the EU Directive on mechanical vibration

Data are given as numbers (\%). See text for the definition of the measures of daily vibration exposure $\left(A(8)_{\text {sum }}, A(8)_{\text {max }}, \mathrm{VDV}_{\text {sum }}, \mathrm{VDV}_{\text {max }}\right)$.

\begin{tabular}{lccccr}
\hline $\begin{array}{l}\text { Measures of daily } \\
\text { vibration exposure }\end{array}$ & & \multicolumn{5}{c}{ Drivers } \\
\cline { 2 - 6 } & & $\begin{array}{c}\text { Group A } \\
(\mathrm{n}=49)\end{array}$ & $\begin{array}{c}\text { Group B } \\
(\mathrm{n}=67)\end{array}$ & $\begin{array}{c}\text { Group C } \\
(\mathrm{n}=86)\end{array}$ & $\begin{array}{r}\text { Total sample } \\
(\mathrm{n}=202)\end{array}$ \\
\hline$A(8)_{\max }\left(\mathrm{ms}^{-2}\right.$ r.m.s. $)$ & & & & & \\
& $<0.5$ & $39(79.6)$ & $54(80.6)$ & $86(100)$ & $179(88.6)$ \\
& $>0.5$ & $10(20.4)$ & $13(19.4)$ & $0(0)$ & $23(11.4)$ \\
\hline$A(8)_{\text {sum }}\left(\mathrm{ms}^{-2}\right.$ r.m.s. $)$ & & & & & \\
& $<0.5$ & $20(40.8)$ & $48(71.4)$ & $86(100)$ & $154(76.2)$ \\
& $>0.5$ & $29(59.2)$ & $19(28.4)$ & $0(0)$ & $48(23.8)$ \\
\hline $\mathrm{VDV}_{\max }\left(\mathrm{ms}^{-1.75}\right)$ & & & & & \\
& $>9.1$ & $19(38.8)$ & $32(47.8)$ & $86(100)$ & $137(67.8)$ \\
& $>9.1$ & $30(61.2)$ & $35(52.2)$ & $0(0)$ & $65(32.2)$ \\
\hline $\mathrm{VDV}_{\text {sum }}\left(\mathrm{ms}^{-1.75}\right)$ & & & & & \\
& $>9.1$ & $14(28.6)$ & $31(46.3)$ & $77(89.5)$ & $122(60.4)$ \\
& $>9.1$ & $35(71.4)$ & $36(53.7)$ & $9(10.5)$ & $80(39.6)$ \\
\hline
\end{tabular}

The EU Directive on mechanical vibration ${ }^{7)}$ has established daily exposure action values of either $A(8)_{\max } 0.5 \mathrm{~ms}^{-2}$ r.m.s. or $\mathrm{VDV}_{\max } 9.1 \mathrm{~ms}^{-1.75}$ to reduce the risks from WBV at the workplace. In this study, 23 drivers (11.4\%) were exposed to $A(8)_{\max }$ greater than the daily exposure action value of $0.5 \mathrm{~ms}^{-2}$ r.m.s., while this figure increased to 48 drivers $(23.8 \%)$ when the action value was expressed in terms of $A(8)_{\text {sum }}$, and to 65 drivers $(32.2 \%)$ when the action value was expressed as $\mathrm{VDV}_{\max }$ (Table 8). Of those exposed to $\mathrm{VDV}_{\max }$ $>9.1 \mathrm{~ms}^{-1.75}$, there were 30 drivers of earth-moving machines (61.2\% of Group A), 35 drivers of fork-lift trucks $(52.2 \%$ of Group B), and none among drivers of public utility vehicles (Group C). As a result, in our study $21 \%$ of the drivers would be excluded from prevention programmes if $A(8)_{\max }$, instead of $\mathrm{VDV}_{\max }$, was chosen as the preferred measure of daily vibration exposure. A greater number of drivers $(n=80$, $39.6 \%$ ) would be eligible for compulsory health surveillance if VDV (see Eq. 4) was estimated on the basis of summation over axes $\left(\mathrm{VDV}_{\text {sum }}\right)$. To support the opinion that health surveillance should not be limited to workers exposed to $A(8)_{\max }$ $>0.5 \mathrm{~ms}^{-2}$ r.m.s., Figure 1 shows that the cumulative incidence of 12-month LBP, high pain intensity and disability in the lower back of our professional drivers tended to increase progressively from $A(8)_{\max }$ to $\mathrm{VDV}_{\text {sum }}$ for daily vibration exposure greater than the action values established by the EU Directive.

The findings of this prospective cohort study suggest that healthy professional drivers with regular daily vibration exposure are at risk of developing low back symptoms over a twoyear follow-up period. There are few longitudinal studies of WBV exposed workers in the available literature. In a series of retrospective cohort studies of disability and long term sick leave due to back disorders in Dutch crane operators and tractor drivers, the incidence of all back disorders and lumbar disc disorders was greater in the WBV exposed groups than in unexposed controls ${ }^{27-29)}$. In a German study, the four-year incidence of 'lumbar syndrome' in $111 \mathrm{WBV}$ exposed workers with no low back symptoms at baseline varied from $46 \%$ in the low exposure group to $67 \%$ in the high exposed group ${ }^{30)}$.

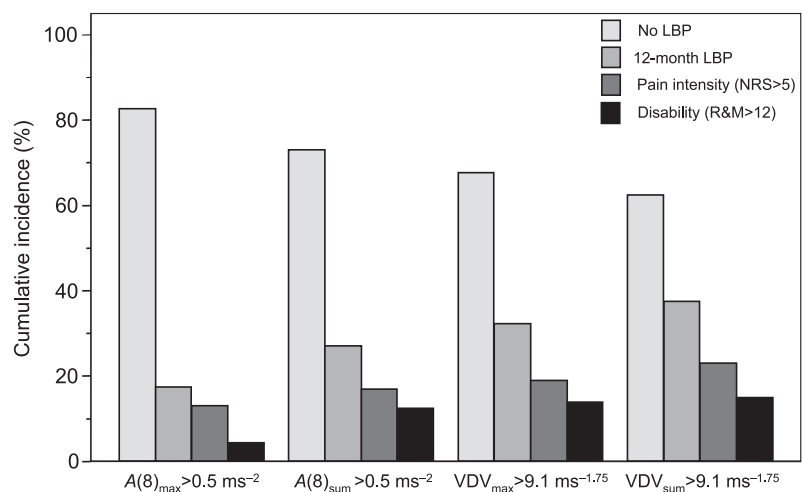

Fig. 1. Cumulative incidence of 12-month low back pain (LBP), high pain intensity (Numerical Rating Scale (NRS) score $>5$ ), and disability due to the last episode of LBP in the previous 12 months (Roland and Morris (R\&M) disability scale score > 12) in the professional drivers according to measures of daily vibration exposure dichotomised at the daily exposure action values established by the Directive of the European Union on mechanical vibration. $A(8)_{\max }$ (highest axis) and $A(8)_{\text {sum }}$ (root-sum-of-squares) are the 8 -h energy-equivalent frequency-weighted acceleration magnitude in $\mathrm{ms}^{-2}$ r.m.s., respectively. $\mathrm{VDV}_{\max }$ (highest axis) and $\mathrm{VDV}_{\text {sum }}$ (root-sum-ofquads) in $\mathrm{ms}^{-1.75}$ are the vibration dose value, respectively.

In the VIBRISKS survey conducted in the Netherlands, the one-year incidence of LBP in a cohort of 229 WBV exposed operators was estimated around $25 \% 31,32$ ). In our cohort study, the cumulative incidence of 12-month LBP over a twoyear follow up period ranged from $35 \%$ in the driver group with lower WBV exposure (public utility vehicles) to $47 \%$ in the group with higher exposure (earth-moving machines). Differences in LBP incidence between studies may be due to several factors, among which sample sizes, length of the follow-up period, and magnitude of vibration exposures.

In this study, multivariate data analysis showed that measures of daily vibration exposure averaged according to the fourth power method (i.e. VDV) performed better for the 
prediction of LBP outcomes than measures which assume a second power time dependency (i.e. A(8)). Test for trends and the pattern of the proportional odds ratios suggest that exposure-response relationships were more evident when WBV exposure was expressed in terms of $\mathrm{VDV}_{\text {sum }}$ or $\mathrm{VDV}_{\max }$ rather than $A(8)_{\text {sum }}$ or $A(8)_{\max }$, respectively. The fourth power averaging procedure (r.m.q.), compared with the second power averaging method (r.m.s.), increases the severity of vibration containing peaks or shocks. In this study, the magnitude of the crest factors of vibration generated by the machinery suggests that the drivers of earth-moving machines and fork-lift trucks were exposed to impulsive vibration to a greater extent than drivers of public utility vehicles. Considering that LBP outcomes were more severe in the drivers of heavy machines, it is not unexpected that exposure-response relationships are more likely to emerge from measures of vibration exposure which include frequency-weighted r.m.q. acceleration rather than r.m.s. acceleration.

Duration of daily exposure to WBV also provided good indications of the risk for LBP outcomes over time. This finding is consistent with those reported in other epidemiological studies $31,33,34)$. In the Dutch study of the VIBRISKS project $^{31)}$, daily exposure duration was significantly associated with driving-related LBP (i.e. LBP during or immediately after driving a vehicle), and, to a lesser extent, with 12-month LBP over one-year follow-up period. By contrast, the Dutch authors did not observe significant associations with other measures of daily vibration exposure. These findings may suggest that more importance should be given to daily exposure duration in the current standards and directives for the protection of workers against the adverse health effects of WBV.

In this study, a physical work load index, derived from combining manual materials handling and awkward postures, was a significant predictor of all LBP outcomes. The excess risk for duration of LBP, pain intensity and disability tended to increase with the increase of physical load grade. These findings are consistent with those of several epidemiological studies, reviews and meta-analyses which concluded that there is strong evidence for a positive relationship between (low) back disorders and lifting loads, frequent trunk bending and twisting, and WBV exposure at workplace $\left.{ }^{1,4}, 5,31,35\right)$. This view is also supported by the findings of experimental investigations which showed that non-neutral trunk postures can combine with seated WBV exposure to increase the risk of degenerative changes in the spine ${ }^{21}, 23,36$ ).

This study showed no clear evidence of an association between LBP outcomes and work-related psychosocial factors. Our findings of a weak association between work-related psychosocial factors and LBP outcomes over time seems to reflect the contradictory picture emerging from the review of the scientific literature on the subject. Some authors reported that low workplace social support, low job satisfaction, and low job decision latitude are risk factors for musculoskeletal disorders (back pain included), even though the magnitude of this evidence varied across different studies and study designs $^{4,6}, 37$ ). To the contrary, a systematic review of 40 prospective cohort studies found insufficient evidence for positive association between LBP and the aforementioned psychosocial risk factors at work ${ }^{38)}$. The authors pointed out the heterogeneity of the reviewed studies, mainly with reference to the different definitions of LBP and psychosocial factors used in the various investigations, the variety of instruments to collect exposure and outcome data, and the lack of standardisation for the metric used to quantify psychosocial variables. In the light of these major methodological problems, and considering that the possible aetiological mechanisms are poorly understood, the reviewers concluded that randomness for the associations reported in some studies cannot be excluded.

This study has some limitations. Quantification of duration of daily exposure to WBV may be difficult because recall bias cannot be ruled out when daily driving time is estimated by means of questionnaire or direct interview of employees and employers. To reduce, at least partially, this bias, a survey was conducted in the field to compare subjective estimates of daily exposure duration with objective measurements of actual driving time during typical working days ${ }^{17}$. Systematic observations of the variability of work tasks over a one-week period indicated that drivers tended to overestimate the duration of their actual exposure to $\mathrm{WBV}$ in the range 5 to $13 \%$ (mean 11\%). This finding is broadly consistent with the results of a national survey in Great Britain which showed a good agreement between reported and observed duration of exposure to $\mathrm{WBV}$ in a sample of drivers of industrial and agricultural machines (median ratio of reported to observed time: 1.1 , interquartile range: 1.0 to 1.2$)^{39)}$. A further uncertainty in the estimation of daily vibration exposure may arise because vibration measurements were made on currently available machines or vehicles, even though a limited number of vibration measurements were also performed on old machinery, mainly in dockyards. However, it was mentioned above that the weighted r.m.s. acceleration magnitude of vibration measured in the vehicles of the present study are comparable with those published in other reports $1,3,8,21-26$ ).

Longitudinal studies involving outcomes and exposure variables that vary over time may be affected by feedback bias: drivers with LBP may modify their exposure to $\mathrm{WBV}^{40}$. Although the sample of this study included drivers not affected with LBP at baseline, this potential bias cannot be excluded. Information on driving activities gathered from repeated interviews of the drivers did not reveal substantial changes in exposure associated with the onset of LBP during the followup period. Moreover, transition modelling of data did not show significant interactions between measures of vibration exposure and previous episodes of low back symptoms, suggesting that feedback bias, if any, should not have affected the exposure-response relationships observed in this study.

\section{Conclusions}

In this longitudinal study of professional drivers, alternative measures of daily vibration exposure were found to be associated with the risk of developing LBP over time. Data analysis with a transition model, which takes into account the temporal sequence between cause and effect and captures the longitudinal part of the relationship, suggested that measures of daily vibration exposure averaged according to the fourth power method $\left(\mathrm{VDV}_{\text {sum }}\right.$ or $\left.\mathrm{VDV}_{\max }\right)$ were better predictors of LBP outcomes over time than measures which assume a second power time dependency $\left(A(8)_{\text {sum }}\right.$ or $\left.A(8)_{\max }\right)$. A simple 
measure of duration of daily exposure to hazardous vibration also provided good predictions of the risk for LBP. Physical work load, but not psychosocial environment, was significantly associated with the occurrence of LBP outcomes over time.

\section{Acknowledgements}

This research was supported by the European Commission under the Quality of Life and Management of Living Resources programme - Project No. QLK4-2002-02650 (VIBRISKS).

\section{References}

1) Bovenzi M, Hulshof CTJ (1999) An updated review of epidemiologic studies on the relationship between exposure to whole-body vibration and low back pain (1986-1997). Int Arch Occup Environ Health 72 351-65.

2) Comité Européen de Normalisation (1996) Mechanical vibration guide to the health effects of vibration on the human body. CR Report 12349. CEN, Brussels.

3) Bongers PM, Boshuizen HC (1990) Back disorders and wholebody vibration at work. Academisch Proefschrift. Universiteit van Amsterdam, Amsterdam.

4) Burdorf A, Sorock G (1997) Positive and negative evidence on risk factors for back disorders. Scand J Work Environ Health 23, 243-56.

5) National Institute for Occupational Safety and Health (1997) Musculoskeletal disorders and workplace factors - a critical review of epidemiologic evidence for work-related musculoskeletal disorders of the neck, upper extremity, and low back. DHHS (NIOSH) Publication No. 97-141, Cincinnati.

6) Bongers PM, de Winter CR, Kompier MAJ, Hildebrandt VH (1993) Psychosocial factors at work and musculoskeletal disease. Scand Work Environ Health 19, 297-312.

7) Directive 2002/44/EC of the European Parliament and the Council of 25 June 2002 on the minimum health and safety requirements regarding the exposure of workers to the risks arising from physical agents (vibration) (sixteenth individual Directive within the meaning of Article 16(1) of Directive 89/391/EEC). Official Journal of the European Communities, L 117/13, 6.7.2002.

8) VIBRISKS (2007) Risks of Occupational Vibration Exposures. FP5 Project No. QLK4-2002-02650. European Commission Quality of Life and Management of Living Resources Programme. http://www. vibrisks.soton.ac.uk Accessed February 8, 2009.

9) Pinto I, Bovenzi M (2007) Italian translation of VIBRISKS questionnaire for whole body vibration. Supplement 2 to Annex 12 to VIBRISKS Final Technical Report: Risks of Occupational Vibration Exposures-VIBRISKS. FP5 Project No. QLK4-2002-02650. European Commission Quality of Life and Management of Living Resources Programme. http://www.vibrisks.soton.ac.uk. Accessed February 8, 2009.

10) Pope M, Magnusson M, Lundström R, Hulshof CTJ, Verbeek J, Bovenzi M (2002) Guidelines for whole-body vibration health surveillance. J Sound Vib 253, 131-67.

11) Bovenzi M, Rui F, Negro C, D'Agostin F, Angotzi G, Bianchi S, Bramanti L, Festa GL, Gatti S, Pinto I, Rondina L, Stacchini N (2006) An epidemiological study of low back pain in professional drivers. J Sound Vib 298, 514-39.

12) Kuorinka I, Jonsson B, Kilbom A, Vinterberg H, Biering-Sørensen F, Andersson G, Jørgensen K (1987) Standardised Nordic Questionnaire for the analysis of musculo-skeletal symptoms. Appl Ergon 18, 233-7.

13) von Korff M, Jensen MP, Karoly P (2000) Assessing global pain severity by self-report in clinical and health services research. Spine 25, 3140-51.

14) Roland M, Morris R (1983) A study of the natural history of back pain. Part 1: development of a reliable and sensitive measure of disability in low-back pain. Spine 8, 141-4.

15) Lundström R (2007) Protocol for epidemiological studies of wholebody vibration. Annex 12 to VIBRISKS Final Technical Report: Risks of Occupational Vibration Exposures - VIBRISKS. FP5 Project No. QLK4-2002-02650. European Commission Quality of Life and Management of Living Resources Programme. http://www.vibrisks. soton.ac.uk. Accessed February 8, 2009

16) ISO 2631-1 (1997) Mechanical vibration and shock - guide for the evaluation of human exposure to whole- body vibration - part 1 : general requirements. International Organization for Standardization, Geneva.

17) Pinto I, Stacchini N (2006) Uncertainty in the evaluation of occupational exposure to whole body vibration. J Sound Vib 298, 556-62.

18) Karasek RA (1979) Job demands, job decision latitude, and mental strain: implications for job redesign. Adm Sci Q 24, 285-307.

19) Rabe-Hesketh S, Skrondal A (2005) Multilevel and longitudinal modeling in Stata. Stata Press, College Station, Texas.

20) Twisk JWR (2003) Applied longitudinal data analysis for epidemiology. A practical guide. Cambridge University Press, Cambridge

21) Dupuis H, Zerlett G (1986) The effects of whole-body vibration. Springer-Verlag, Berlin.

22) Bovenzi M, Zadini A (1992) Self-reported low back symptoms in urban bus drivers exposed to whole-body vibration. Spine 17, 1048-59.

23) Griffin MJ (1990) Handbook of human vibration. Academic Press, London.

24) Griffin MJ, Howarth HVC Pitts PM, Fischer S, Kaulbars U, Donati, PM, Bereton PF (2006) Guide to good practice on whole-body vibration. European Commission Directorate General Employment, Social Affairs and Equal Opportunities (contract VC/2004/0341), Brussels.

25) International Social Security Association (1989) Vibration at work. International Section Research, Institut National de Recherche et de Sécurité. INRS, Paris.

26) Paddan GS, Haward BM, Griffin MJ, Palmer KT (1999) Whole-body vibration: evaluation of some common sources of exposure in Great Britain. Health and Safety Executive. The Stationery Office, London.

27) Bongers PM, Boshuizen HC, Hulshof CTJ (1990) Disability due to back disorders in crane operators in a metal construction company; short comunication. Academisch Proefschrift, 145-52, Universiteit van Amsterdam, Amsterdam.

28) Bongers PM, Boshuizen HC, Hulshof CTJ, Koemeester AC (1988) Back disorders in crane operators exposed to whole-body vibration. Int Arch Occup Environ Health 60, 129-37.

29) Boshuizen HC, Hulshof CTJ, Bongers PM (1990) Long-term sick leave and disability pensioning due to back disorders of tractor drivers exposed to whole-body vibration. Int Arch Occup Environ Health 62, $117-22$

30) Schwarze S, Notbohm G, Dupuis H, Hartung E (1998) Dose-response relationships between whole-body vibration and lumbar disk disease - a field study on 388 drivers of different vehicles. J Sound Vib 215, 613-28.

31) Tiemessen IJH, Hulshof CTJ, Frings-Dresen MHW (2008) Low back pain in drivers exposed to whole body vibration: analysis of a doseresponse pattern. Occup Environ Med 65, 667-75.

32) Tiemessen IJH (2008) Occupational whole-body vibration and low back pain: strategies to reduce exposure. Academisch Proefschrift. Universiteit van Amsterdam, Amsterdam.

33) Pietri F, Leclerc A, Boitel L, Chastang JF, Morcet JF, Blondet M (1992) Low-back pain in commercial travellers. Scand J Eork Environ Health 18, 52-8.

34) Chen JC, Chang WR, Chang W, Christiani D (2005) Occupational factors associated with low back pain in urban taxi drivers. Occup Med (Lond) 55, 535-40.

35) Riihimäki H, Viikari-Juntura E, Moneta G, Kuha J, Videman T, Tola $S$ (1994) Incidence of sciatic pain among men in machine operating, dynamic physical work, and sedentary work. A three-year follow up. Spine 19, 138-42.

36) Wilder DG (1993) The biomechanics of vibration and low back pain. Am J Ind Med 23, 577-88.

37) Hoogendoorn WE, van Poppel MNM, Bongers PM, Koes BW, Bouter LM (2000) Systematic review of psychosocial factors at work and private life as risk factors for back pain. Spine 25, 2114-25.

38) Hartvigsen J, Lings S, Leboeuf-Yde C, Bakketeig L (2004) Psychosocial factors at work in relation to low back pain and consequences of low back pain: a systematic, critical review of prospective cohort studies. Occup Environ Med 61, 1-10 (electronic review, http:// www.occenvmed.com/cgi/content/ full/61/1/e2).

39) Palmer KT, Haward B, Griffin MJ, Bendall H, Coggon D (2000) Validity of self-reported occupational exposures to hand-transmitted and whole-body vibration. Occup Environ Med 57, 237-41.

40) Eisen EA (1999) Methodology for analyzing episodic events. Scand J Work Environ Health 25 (Suppl 4), 36-42. 